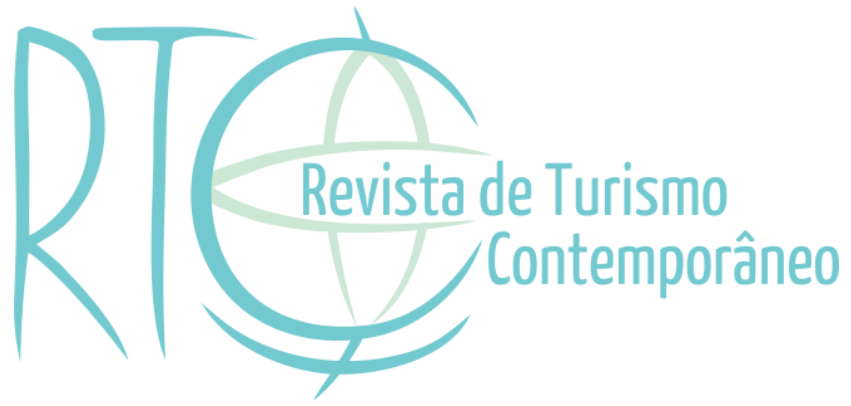

\title{
A percepção de inovação dos gestores das micro e pequenas empresas turísticas, localizadas no bairro da Praia Grande, Centro Histórico de São Luís-MA Perception of the innovation by the managements of micro and small tourism companies, located in Praia Grande district, Centro Histórico de São Luís-MA
}

Gilson de Jesus Mota Rodrigues

Professor do Instituto Federal de Educação, Ciência e Tecnologia do Maranhão -IFMA, São Luiz/MA, Brasil.

E-mail: gilson.dejesus@ifma.edu.br

Francisco Antônio dos Anjos

Professor e coordenador do Programa de Mestrado e Doutorado em Turismo e Hotelaria da Universidade do Vale do Itajaí -UNIVALI, Florianópolis/SC, Brasil. E-mail: anjos@univali.br 


\title{
RESUMO
}

Este estudo tem por objetivo verificar a percepção, sobre inovação, dos gestores das MPE's turísticas no bairro da Praia Grande, Centro Histórico de São Luís-MA. A pesquisa se caracteriza como quantitativa, sendo realizada por meio de um questionário fechado formado por 4 constructos para a medição da percepção sobre inovação dos gestores das MPE's. Foram respondidos 43 questionários dos segmentos artesanato, restauração e outros empreendimentos turísticos. O resultado aponta que os gestores possuem no geral uma boa percepção sobre inovação. As maiores observações são relacionadas ao construto confiança como fator para inovar, em que existe uma incoerência relacionada à liberdade no processo de inovação, bem como, dificuldade para inovar, pois a maior parte dos gestores não sente dificuldade para inovar devido a grande quantidade de empresas no mercado.

Palavras-chave: Inovação. Serviços Turísticos. MPE’s Turísticas.

\begin{abstract}
This study aimed to verify the perception on innovation, managers of MSEs tourist in the neighborhood of Praia Grande, Centro Histórico de Sao Luís, MA. The research is characterized as quantitative being carried out through a closed questionnaire composed of four constructs for measuring the perception of innovation managers of MSEs. They were answered 43 questionnaires craft segments, catering and other tourism enterprises. The result indicates that managers have in general a good insight into innovation. The major findings are related to construct confidence as a factor for innovation, where there is an inconsistency related to freedom in the innovation process, as well as difficulty to innovate because most managers do not find it difficult to innovate due to the large number of companies in the market.
\end{abstract}

Keywords: Innovation. Tourism Services. Tourist SME's. 


\section{INTRODUÇÃO}

No Brasil, devido sua grande extensão e diversificação, seja: ambiental, econômica, cultural, climática, entre outras, cria-se a possibilidade de exploração/desenvolvimento de diversos produtos turísticos. As demandas, seja para turismo de sol e praia, seja para o turismo de negócios, ou mesmo, turismo cultural, entre outros, criam espaços/possibilidades para a abertura dos mais diversos empreendimentos como: hotelaria, restauração, transporte, agências de viagens, animação/recreação, informação, etc.

Sendo assim, é necessária cada vez maior competência dos gestores, com a capacidade de inovação para superar os desafios e a concorrência. Devido à grande difusão do turismo pelo mundo, as organizações turísticas precisam a cada momento empreender de modo a criar ambientes propícios a inovação, por meio da mesma, a inserção nas opções de mercados mais procurados pelos turistas estará garantida.

É exigido ao empreendedor não apenas a criação, inovação e a capacidade de lançar no mercado algo novo, mas, inclusive, a capacidade de compreender todas as forças que atuam no ambiente no qual se está inserindo. Ainda que a novidade seja um novo produto, um inovador sistema de distribuição ou até mesmo um método para desenvolver uma nova estrutura organizacional, o empreendedor precisa entender todo o ambiente. (Valei, Wilkinson \& Amâncio, 2008). Para Gândara (2010), o turismo é competitividade e concorrência, logo, crescer do ponto de vista turístico é uma necessidade. Os empreendedores turísticos necessitam entender que dentro de um mercado globalizado, como é o serviço turístico, a cada momento, os mesmos devem buscar formas inovadoras que possibilitem seu diferencial, em relação aos concorrentes. Segundo, Lima e Alves (2011) num contexto de crise, a inovação aparece como ponte para a organização encontrar seu próprio método de gerir as mudanças e assim se destacar, garantindo de alguma forma uma permanência mais duradoura no mercado. Devido os pontos positivos da inovação, cada vez mais, os principais setores produtivos procuram inovar. Tanto no setor de serviços, quanto no turismo, são reunidos esforços, recursos e estímulos à implementação do processo inovador, pois "as ideias emergem a partir de fontes de ideias ou da solução criativa de problemas, elas precisam de um desenvolvimento e aperfeiçoamento posteriores até o oferecimento do produto ou serviço final", assim completam Hisrich e Peters (2004, p. 171).

A pesquisa tem como objeto de estudo, as micro e pequenas empresas - MPE's turísticas localizadas no bairro da Praia Grande. A partir do Programa de Preservação e 
Revitalização do Centro Histórico de São Luís [PPRCH/SL], denominado Projeto Reviver, teve ações direcionadas no sentido de elevar turisticamente. Por meio do programa, o bairro da Praia Grande passou a adquirir representatividade, que anteriormente vinculado às atividades de vivência, trabalho ou moradia pelos residentes, passou a ter reflexos diretos no valor atribuído, sobretudo, por meio do turismo, no relacionamento dos moradores com o patrimônio (Carvalho \& Simões, 2011; Silva, 1997). O objetivo deste artigo é verificar a percepção, sobre inovação, dos gestores das MPE's turísticas localizadas no bairro da Praia Grande, Centro Histórico de São Luís-MA, criando subsídios para o fortalecimento do setor, possibilitando pesquisas futuras.

\section{REVISÃO TEÓRICA}

\subsection{INOVAÇÃO}

Em qualquer área que se atue, a inovação é parte crucial no empreendedorismo, pois dentro de um mercado, com produtos e serviços cada vez mais parecidos e/ou substitutos é o que possibilita consequentemente, diferenciação e ganhos superiores em relação aos concorrentes. Para Penalva (2015), a história da Google é apenas mais uma entre muitas de grandes ideias que foram subestimadas.

Say (1767-1832) contribuiu para o pensamento econômico ao enfatizar o empreendedorismo como o quarto fator da produção junto com os fatores mais tradicionais: terra, trabalho e capital (Brue, 2006). Para Drucker (1985), o conhecimento seria um fator de produção mais importante que os fatores mais tradicionais, sendo assim, a visão empreendedora não permite que o conhecimento seja estagnado.

A inovação é um instrumento específico do espírito empreendedor. A capacidade de criar riqueza - a inovação, portanto, é uma questão econômica ou social, mais do que uma questão técnica. Os empreendedores bem sucedidos, quaisquer que sejam suas motivações pessoais, não se contentam em criar algo novo, querem fazer uma contribuição (Drucker, 2014). De acordo com Penalva (2015), Tiara Bicalho, gerente de Projetos de Inovação da Iventta BGI, afirma que, no período taylorista e fordista as empresas se preocupavam com a produtividade (produzir mais gastando menos). Depois a prioridade a qualidade, e na contemporaneidade o foco está na inovação como estratégia competitiva de mercado. 
A inovação é uma das principais vertentes da vantagem competitiva, pois para atingir os objetivos e responder às responsabilidades impostas pela sociedade, as organizações têm de adaptar as suas atividades às várias pressões do ambiente, em constante mudança. Logo, as empresas necessitam de inovação para sobreviverem, do contrário, correndo o risco de morte. Sendo assim, a inovação é o melhor modo para garantir a continuidade de uma empresa (Bouchikhi \& Kimberly, 2001; A. Braga, Marques \& V. Braga, 2009; Porter, 1999).

Existem várias formas de se conceituar inovação. Schumpeter (1961), diz que os novos bens de consumo, os novos métodos de produção ou transporte, os novos mercados e as novas formas de organização industrial, criados pelas empresas, contribuem para o funcionamento do capitalismo, existindo um processo de destruição criadora, onde toda empresa capitalista precisa se adaptar. Para o mesmo, antes, o que importava era a concorrência de preços, passado a concorrência e o esforço de vendas, a concorrência que alicerça e determina a própria existência na superioridade de custos, qualidade, margem de lucros e a produção das firmas, é a concorrência de novas mercadorias, novas técnicas, novas fontes de suprimento e novos tipos de organização (unidade de controle na maior escala possível).

A Lei n.10.973/2004 entende a inovação com a "introdução de novidade ou aperfeiçoamento no ambiente produtivo ou social que resulte em novos produtos, processos ou serviços” Lei n.10.973 (2004).

De acordo com a Fundação Nacional de Qualidade [FNQ] (2008): “[...] inovação é muito mais que o desenvolvimento de novas tecnologias, produtos e serviços. Envolve a criação de novos modelos de negócios, novas formas de atender necessidades dos consumidores, novos processos organizacionais, novos meios de competir e cooperar no ambiente empresarial".

Em estudo publicado no Manual de Oslo, segundo a Organização para Cooperação e Desenvolvimento Econômico [OECD] (2004), as inovações podem ser enquadradas como de produto, de processo, de marketing ou organizacional. As atividades que as empresas empreendem para inovar são de dois tipos: P\&D (pesquisa básica, aplicada ou desenvolvimento experimental) e outras atividades não relacionadas com $\mathrm{P} \& \mathrm{D}$, envolvendo a aquisição de bens, serviços e conhecimentos externos. Instituto Brasileiro de Geografia e Estatística [IBGE] (2012).

Inovar é adotar novas tecnologias que aumentam a competitividade da companhia (Hamel \& Prahalad, 2005). A inovação representa a possibilidade de um desenvolvimento diferenciado e, especificamente, responde por aumentos na produtividade e pela oportunidade 
de novos patamares de vantagem competitiva, sendo a capacidade inovadora, portanto, um elemento crucial para a avaliação do potencial de um setor da economia (Quandt, 2009).

Motivação é considerada uma razão social para inovar, pois inovação é a aplicação da criatividade na solução de um problema ou na criação de algo que atenda as necessidades ou desejos do mercado. (Siqueira, 2009).

A inovação é dividida, por Drucker (2014), em três: técnica, econômica e social, sendo as duas últimas mais importantes. Para o autor a compra a prestação é uma inovação econômica, que possibilitou ao fazendeiro do século XIX que, virtualmente, não tinha nenhum poder aquisitivo, pagar com ganhos futuros. O mesmo, também, cita que a tecnologia pode ser importada a custos baixos, e com um mínimo de risco cultural. Instituições pelo contrário, precisam de raízes culturais para crescer e prosperar. Uma locomotiva que vai puxar um trem de Londres a Liverpool irá, da mesma forma, sem adaptação ou mudança, puxar um trem de Tóquio a Osaka. Citando os japoneses, Drucker informa que, os mesmos concentraram seus recursos em inovações sociais, no puro estilo judô, para imitar, importar e adaptar inovações técnicas, com um sucesso surpreendente. O autor deixa claro que os empreendedores precisam aprender a praticar a "inovação sistemática", que consiste na busca deliberada e organizada de mudanças, e na análise sistemática das oportunidades, que tais mudanças podem oferecer para a inovação econômica e social, e não esperar a "ideia brilhante".

A inovação pode ser dividida em: incrementais, semi-radicais e radicais. Incrementais são aqueles em que há melhorias moderadas nos produtos e processos de negócios em vigor, no outro extremo, a radical é o conjunto de novos produtos e/ou serviços fornecidos de maneiras inteiramente novas. A inovação semi-radical envolve mudança substancial no modelo de negócios ou na tecnologia de uma organização, mas não em ambas (Davila, Epstein, \& Shelton, 2007).

A melhor definição de inovação em serviços, deriva das teorias de marketing, propostas por Kotler (1993), entendendo que os paradigmas clássicos conhecidos, como o econômico-tecnológico (mais apropriado para explicar inovações tecnológicas), e o empreendedorismo (mais apropriado para compreender o estabelecimento de novas empresas, mesmo as de serviço), não são os mais adequados para estudar as inovações em serviços (Sundbo, 1997). Dessa forma, Sundbo e Gallouj (1998) apresentam quatro tipos de inovações em serviços: 
Inovações de produto (serviço): criação e/ou fornecimento de um novo serviço, por exemplo, uma nova linha de financiamento, o atendimento de uma nova especialidade médica, um novo tipo de seguro;

Inovações de processo: são as novas formas de produzir e fornecer um serviço.

Dividindo-se em duas categorias: uma relacionada com os processos de produção, back office e a outra com os processos de atendimento e entrega ao cliente, front office;

Inovações organizacionais: referem-se à introdução de novas maneiras de gerenciamento, como o (TQM) - Gerenciamento da Qualidade Total, autogerenciamento de grupos, etc.;

Inovações de mercado: relacionadas com a descoberta de novos mercados, como a segmentação de mercado.

Outra forma de inovação sugere Sundbo e Gallouj (1998), chamada de ad hoc, que desempenha um papel significativo especialmente em empresas de serviços intensivas em conhecimento, como as consultorias e empresas de engenharias. Esse tipo de inovação referese à construção de soluções adequadas aos problemas apresentados pelos clientes. Os autores informam que as inovações em empresas de serviços são em sua maioria, incrementais, constituídas de pequenos ajustes e facilmente imitadas por seus competidores. Os autores apontam que grande parte das inovações em serviços está voltada para atender às necessidades dos clientes e para a formação de recursos humanos para a execução dos serviços. Para tanto, de um modo geral, são feitos investimentos incrementais nos processos e procedimentos, não sendo necessários grandes níveis de pesquisa e desenvolvimento.

Tiara Bicalho, considera que uma nova ideia na empresa pode surgir das pessoas que estão no dia a dia na operação. Informa ainda que a inovação deve vir acompanhada de uma mudança cultural na organização, cabendo ao gestor prover a mudança e trabalhar a estratégia de inovação aos objetivos da empresa (Penalva, 2015).

A confiança é fator fundamental para se estabelecer e preservar um ambiente de trabalho produtivo, gerando segurança e certeza, dois pré-requisitos para inovação e criatividade. A desconfiança, ao contrário, produz frustação, insegurança e medo, que são os maiores obstáculos ao desenvolvimento do pensamento criativo e da ação inovadora. Está claro que todo ser humano nasce com a capacidade de encontrar e resolver problemas complexos, e quando tal comportamento criativo é aproveitado entre um grupo de pessoas com diferentes habilidade e perspectivas, coisas extraordinárias podem ser alcançadas (Bessant, \& Tidd, 2009; Rush, 2005). 
O homem é o principal ator na inovação. A partir dele é que as organizações de qualquer porte, poderão se estabelecer no mercado em que atuam, sendo que os recursos financeiros, materiais, informacionais, espaço e tempo são secundários no processo.

O ser humano, de acordo com Penalva (2015), é ponto de partida de todo o processo de inovação, dotado de criatividade e capacidade de experimentação. Rodrigues e Silva (1998) defendem que a criatividade seja promovida por toda a organização, pois o maior número de participantes levaria a uma maior quantidade e qualidade de ideias.

Entretanto, de acordo com Brue (2006), Schumpeter (1950) faz um alerta informando que, as inovações não ocorrem de forma contínua, e sim, em grupos. A maioria dos empresários empreendedores e arrojados cria a partir de suas atividades um clima favorável em onde outros podem segui-los. Há aumento no crédito, nos preços e na renda, fazendo a prosperidade prevalecer. Porém, não é sempre assim, pois o boom econômico gera condições desfavoráveis para o seu processo contínuo. Ao ocorrer aumento nos preços, diminui-se o investimento, e a concorrência entre produtos novos e antigos causa perdas econômicas. Quando os empresários pagam suas dívidas, o processo deflacionário é intensificado e a recessão acaba substituindo a prosperidade. As instabilidades econômicas, portanto, representam o processo de adaptação à inovação. O sistema tende ao equilíbrio, exceto quando as inovações sempre quebrem essa tendência. $O$ processo que gera desenvolvimento econômico também gera instabilidades, e cada recessão representa uma luta a favor de um novo equilíbrio.

Tem-se o entendimento que a inovação é crucial aos ganhos que as organizações desejam ter hoje em dia, não só econômicos, mas também, visando uma clientela fiel, parcerias, sustentabilidade, entre outros.

\subsection{INOVAÇÃO EM SERVIÇOS TURÍSTICOS}

A inovação não ocorre apenas no segmento de produtos manufaturados, inúmeros exemplos podem ser encontrados no setor de serviços bancários e seguros on-line: Amazon, no varejo, eBay, mercado de vendas e leilões, Skype, telefonia, Google, publicidade e propaganda. Geralmente, nas grandes economias, o setor de serviços representa a maioria esmagadora de atividades comerciais e laborais, o que significa um potencial significativo. No segmento de assistência a saúde, houve grandes melhorias, exemplos são os Hospitais como o Leicester Royal Infirmary, na Inglaterra, ou o Karolinska Hospital, em Estocolmo, na Suécia, que implementaram melhorias significativas na velocidade, qualidade e eficácia de seus 
serviços em saúde, reduzindo listas de espera para cirurgias eletivas em $75 \%$ e de cancelamento em $80 \%$, por meio da inovação (Bessant \& Tidd, 2009).

A atividade econômica "serviços" passou a fazer parte das atenções acadêmicas após os anos de 1980, anteriormente era preterida (Lima, 2014). Os serviços "são ações, esforços ou desempenhos" (Hoffman \& Bateson, 2009). Para Kotler e Keller (2006) "serviços é qualquer ato ou desempenho, essencialmente intangível, que uma parte pode oferecer a outra e que não resulta na propriedade de nada". Outros dois conceitos de serviços podem ser destacados: "serviço é definido como aplicação de competências especializadas (recursos, conhecimentos e habilidades), por meio de ator, processos e performance para benefício de outra entidade ou da própria entidade" (Vargo \& Lusch, 2004) e "serviço é uma experiência perecível, intangível, desenvolvida para um consumidor que desempenha o papel de coprodutor" (Fitzsimmons \& Fitzsimmons, 2000).

Inovar no setor de produtos, é um desafio para as organizações; pela complexidade do termo e da atividade, em serviços, é ainda mais difícil. Para Gronroos (2004), “os serviços são definidos de maneira ultrapassada". Lovelock e Wright (2004), afirmam que "a maioria das pessoas não encontra dificuldade para definir o setor industrial ou agrícola, mas a definição de serviços pode confundi-las”. Gadrey (2000), diz que: “conceitos vagos e definições difusas de serviços podem levar a classificações e produtos inadequados da indústria, além de encorajar uma modelagem errada para o crescimento dos serviços".

A definição de inovação em serviços utilizada neste trabalho deriva das teorias de marketing, propostas por Kotler (1993), entendendo que os paradigmas clássicos conhecidos, como o econômico-tecnológico (mais apropriado para explicar inovações tecnológicas), e o empreendedorismo (mais apropriado para compreender o estabelecimento de novas empresas, mesmo as de serviço), não são os mais adequados para estudar as inovações em serviços (Sundbo, 1997). Dessa forma, Sundbo e Gallouj (1998) apresentam quatro tipos de inovações em serviços:

I. Inovações de produto (serviço): criação e/ou fornecimento de um novo serviço, por exemplo, uma nova linha de financiamento, o atendimento de uma nova especialidade médica, um novo tipo de seguro;

II. Inovações de processo: são as novas formas de produzir e fornecer um serviço. Dividindo-se em duas categorias: uma relacionada com os processos de produção, back office e a outra com os processos de atendimento e entrega ao cliente, front office; 
III. Inovações organizacionais: referem-se à introdução de novas maneiras de gerenciamento, como o (TQM) - Gerenciamento da Qualidade Total, autogerenciamento de grupos, etc.;

IV. Inovações de mercado: relacionadas com a descoberta de novos mercados, como a segmentação de mercado.

Outra forma de inovação sugerem Sundbo e Gallouj (1998), chamada de ad hoc, que desempenha um papel significativo especialmente em empresas de serviços intensivas em conhecimento, como as consultorias e empresas de engenharias. Esse tipo de inovação referese à construção de soluções adequadas aos problemas apresentados pelos clientes. Os autores informam que as inovações em empresas de serviços são em sua maioria, incrementais, constituídas de pequenos ajustes e facilmente imitadas por seus competidores. Os autores apontam que grande parte das inovações em serviços está voltada para atender às necessidades dos clientes e para a formação de recursos humanos para a execução dos serviços. Para tanto, de um modo geral, são feitos investimentos incrementais nos processos e procedimentos, não sendo necessários grandes níveis de pesquisa e desenvolvimento.

É importante lembrar que a área de gestão de operações vem ultimamente focando a área de serviços muitas vezes adaptando as ferramentas e técnicas tradicionais oriundas da área da manufatura. Essa estratégia adaptativa pode funcionar adequadamente para alguns temas na área de manufatura e serviços, tais como gestão de estoques, gerenciamento de capacidade ou programas de qualidade. Entretanto, pode revelar uma armadilha quando o tema é a inovação, dada a natureza peculiar que o processo de projeto e gestão da operação de serviços possui (Tidd \& Hull, 2005).

Inovação em serviços, para Vasconcellos e Marx (2011, p.445), deve ser conceituada da seguinte forma:

É a introdução de uma característica ou um conjunto de características (tecnológicas ou não tecnológicas) que propiciem a prestação de um serviço para o usuário final de uma nova maneira, ou de uma maneira melhorada. $\mathrm{O}$ usuário final deve reconhecer que o conjunto dessas características seja traduzido como benefício e tenha impacto em sua avaliação da prestação do serviço.

A inovação em serviços surge como uma necessidade de competitividade e adequação às tendências de mercado, com o intuito de melhorar a qualidade, reduzir custos, ou seja, manter a competitividade, as organizações que prestam serviços seguem em busca da inovação (Gorni, Dreher \& Machado, 2009). 
O turismo, mesmo com uma variedade de tipologias, precisa desse diferencial, pois sua demanda exigente e não-fiel, precisa a cada momento ter novas experiências, seja antes, ou depois da viagem. No setor de turismo, outros desafios estão relacionados ao fato de haver tantas pequenas empresas: a necessidade de intermediários para alcançar mercados mais distantes, a dificuldade de comunicação com inúmeras outras empresas e a escassez de pesquisas (Smith, 2006). Uma característica marcante das MPE’s Turística é a falta de experiência dos empresários ao estabelecer o negócio, explicada pelas reduzidas barreiras de entrada no setor (Bramwell \& Lane, 2000; Hall \& Rusher, 2004).

A competitividade das empresas de turismo depende da capacidade de inovação em conseguir custos mais baixos e saídas de maior qualidade que cumpram os requisitos de demanda de clientes em potencial e que introduzam novos produtos (por exemplo, melhores serviços e produtos, personalização, questões ambientais e interação - Instituições Científicas e Tecnológicas -ICT) (Zehrer, Pechlaner, \& Reuter, 2013).

O hotel substituiu as chaves para o acesso aos quartos, por meio do cartão magnético, mas também, criou-se acesso a quartos com chaves, como alternativa a quartos clássicos, outras inovações radicais como os sistemas de reserva e distribuição - GDS e CRS, os sistemas de qualidade oferecidos pelos hotéis, os programas de passageiro frequente para clientes, a internet se tornou um consultor de viagens, a indústria aérea tem diminuído o transporte marítimo de passageiros, os parques temáticos tem afetado os parques de diversões, bem como, uma série de produtos e serviços que não existia antes: turismo de inverno, cruzeiros, negócios, congressos, etc. (Iordache, 2015).

As inovações que as companhias aéreas Southwest Airlines, com uma cultura que estimula os funcionários a buscarem resultados extraordinários, Easyjet, através da filosofia de 70:20:10 - 70\% da aprendizagem decorre no trabalho, 20\% informalmente através de coaching e aconselhamento e 10\% através de aprendizagem formal como programas presenciais e Ryanair, que possui um centro de inovação digital, introduziram no mercado, revolucionaram o transporte aéreo e fortaleceram o setor. (Bessant, Tidd, 2009; Varani, 2009).

Na Serra Gaúcha, a Don Ramon se tornou a primeira pousada e SPA sustentável do Brasil, realizando ações na área ambiental, sociocultural e econômica, interagindo com o ambiente a sua volta e gerando intervenções na comunidade local, promovendo à qualidade de vida a população, seja empregando e capacitando pessoas, ou consumindo e divulgando produtos artesanais da região. A mesma implantou um sistema para perceber quais eram as reais necessidades dos clientes, obtendo como resultado a necessidade para descansar e desestressar. A empresa conta com sistemas de certificação pela Norma da Associação 
Brasileira de Normas Técnicas (ABNT) NBR 15.401, garantido os selos ISO 9001, ISO 14001 e ISO 16001. Restos de sabonete e shampoo gerados pela empresa são reaproveitados por organizações locais para trabalhar em um produto para combater piolho, que posteriormente é enviado a escolas das vizinhanças. Recebeu o Prêmio MPE Brasil e garantiu selos de Excelência TripAdvisor e o Verde do Guia Quatro Rodas, além de destaque com a Rain Forest Alliance. (Zanotto, 2015).

Na Região Uva e Vinho, no munícipio de Garibaldi-RS, o visitante se surpreende ao ser convidado a participar da Oficina Mãos na Massa, onde cada um tem a oportunidade de confeccionar sua colombina, pombinha feita de massa de pão. Após confeccionada, a Osteria oferece um almoço ou jantar, enquanto a pombinha de pão é assada. Ao término das atividades, o turista recebe a colombina, já assada e conta sua história, o que mostra o carinho e a gratidão pela estada do turista na Osteria (Tour da experiência, 2015).

No Rio de Janeiro, o mercado está reinventando as formas tradicionais de fazer turismo. O veículo anfíbio tem capacidade para cerca de 50 pessoas, que podem curtir os principais pontos turísticos do Rio em um passeio ao ar livre que dura aproximadamente 90 minutos e vai do Pão de Açúcar à Baía de Guanabara, criando uma proposta diferente para turistas do Rio. O ponto alto do passeio é o "splashdown", momento em que o veículo sai do asfalto e entra no mar (Valadares, 2014).

No ramo da restauração, inovação é de suma importância para maior viabilidade dos clientes. De acordo com Malzoni e Malzoni (2010), René Redzepi, do restaurante Noma em Copenhague, reinventou a cozinha nórdica, por oferecer uma versão criativa da culinária nórdica com ênfase especial em especialidades regionais.

O turismo é dinâmico e competitivo e exige a capacidade de se adaptar constantemente as necessidades e desejos dos clientes, como a satisfação, a segurança do cliente e diversão que são particularmente o foco das empresas de turismo. É altamente heterogêneo, mas a maioria das empresas são micro empresas com menos de 10 funcionários, contêm pequenas e médias empresas familiares locais, visando a satisfação das necessidades dos clientes locais e as empresas que são parte de redes globais (Dzikowski, 2014).

\section{METODOLOGIA}

Esta pesquisa se concentra em identificar a percepção, sobre inovação, dos gestores nas MPE's turísticas localizadas no bairro da Praia Grande, Centro Histórico de São Luís MA. Foi realizada uma pesquisa exploratória, de caráter descritivo. 
A pesquisa exploratória se refere a criar hipóteses ou mesmo aumentar a familiaridade em relação a determinado tema, por haver pouco conhecimento acumulado e sistematizado (Appolinário, 2009; Vergara, 2011).

O levantamento das empresas foi feito a partir de pesquisa a Junta Comercial do Maranhão - JUCEMA, com uma relação de 74 MPE's turísticas. Após conferência in-loco verificou-se a existência de 72 empresas. Com a não aceitação de alguns gestores em participação da pesquisa, foram entrevistadas 43 MPE’s turísticas encontradas no Bairro Praia Grande - Centro Histórico de São Luís - Maranhão. Deste total, 15 MPE's são de artesanato, 11 MPE's da área de restauração e 17 MPE's de outros segmentos turísticos.

Neste estudo o instrumento de pesquisa se deu pela pesquisa bibliográfica, em que os construtos estão relacionados ao contexto da inovação (Quadro 1).

Quadro 1 - Formação do Instrumento de Pesquisa

\begin{tabular}{|c|c|}
\hline Construto & Base Referencial (Autores) \\
\hline Conceito de inovação & $\begin{array}{l}\text { Schumpeter (1961); Cypriano (1996); Sundbo e } \\
\text { Gallouj (1998); Valdés (2003); OECD (2004); } \\
\text { Andrade (2006); Fornari (2006); Yu e Klement } \\
\text { (2006); Klement (2007); Silva (2007); FNQ (2008); } \\
\text { Rodrigues e Rodrigues (2009); João Claro, Sarmento e } \\
\text { Dias . (2011); Silva (2011); Vasconcellos e Marx } \\
\text { (2011); Bascavusoglu-Moreau, Kopera e Wszendybyl- } \\
\text { Skulska (2013); Boaria (2013); Duarte (2013); Nawrot } \\
\text { (2013); Brasil (2014); Drucker (2014); Sandoval e } \\
\text { Cano (2014); Yazigi (2014); D'arcy e Omar (2015); } \\
\text { Iordache (2015) }\end{array}$ \\
\hline Motivação para inovar & $\begin{array}{l}\text { Cypriano (1996); Valdés (2003); Hamel e Prahalad } \\
\text { (2005); Fornari (2006); Yu e Klement (2006); } \\
\text { Klement (2007); Davila, Epstein e Shelton (2007); } \\
\text { Carvalho (2009); Garrido (2009); Gorni, Dreher e } \\
\text { Machado (2009); Rodrigues e Rodrigues (2009); } \\
\text { Bispo (2011); João et. al. (2011); Brunelli e Macedo- } \\
\text { Soares (2012); IBGE (2012); Nagy (2012); Nogueira } \\
\text { (2012); Bascavusoglu-Moreau, Kopera e Wszendybyl- } \\
\text { Skulska (2013); Boaria (2013); Cardoso e Batista } \\
\text { (2013); Nawrot (2013); Tellechea (2013); Zehrer, } \\
\text { Pechlaner e Reuter (2013); Amazonas (2014); } \\
\text { Meneses e Cunha (2014); Tadeu (2014); Tomazzoni e } \\
\text { Zanirato (2014); Penalva (2015) }\end{array}$ \\
\hline Confiança para inovar & $\begin{array}{l}\text { Rodrigues e Silva (1998); Rush (2005); Bessant e } \\
\text { Tidd (2009); Peccini (2010); Generosi (2011); Maske } \\
\text { (2012); Nogueira (2012); Duarte (2013); Tadeu } \\
\text { (2014); Penalva (2015) }\end{array}$ \\
\hline Dificuldade para inovação & $\begin{array}{l}\text { Bramwell e Lane (2000); Hall e Rusher (2004); } \\
\text { Valdés (2003); Smith (2006); Fornari (2006); Niño } \\
\text { (2009); Trindade (2009); Fortes (2010); Generosi } \\
\text { (2011); Lazzarotti (2012); Nery (2012); Araújo e } \\
\text { Araújo (2013); Bascavusoglu-Moreau, Kopera e } \\
\text { Wszendybyl-Skulska (2013); Duarte (2013); Tejada e } \\
\text { Moreno (2013); Amazonas (2014); Araújo e Ernesto } \\
\text { Filho (2014); Dzikowski (2014); Bâltescu (2015) }\end{array}$ \\
\hline
\end{tabular}

Fonte: Autoria própria 
Para o levantamento das informações foi realizado estudo quantitativo, por meio da coleta de dados aplicada no período de 14 a 18 de setembro de 2015, por meio de um questionário utilizando a escala likert, com os gestores das MPE's, a fim de se identificar através das respostas, qual a percepção das empresas quanto:

1. Conceito de inovação: novos produtos e serviços de maneira totalmente nova, novos métodos de trabalho, expandir para novos mercados, mudança substancial na tecnologia adotada pela organização, adotar algo que foi tentado em outro lugar e que teve sucesso;

2. Motivo pelo qual as empresas inovam: acessar novas tecnologias, acessar novos mercados, aumentar a margem de lucro da empresa, desenvolver uma cultura de mercado, redução de custos;

3. Confiança como fator para estabelecer e preservar um ambiente de trabalho produtivo: pessoas como fonte mais importante dentro do processo de inovação, toda a organização, desde o nível da estrutura mais elevado ao mais baixo, esteja voltada para a inovação; pessoa tenta uma nova iniciativa e falha, há um sério impacto negativo na carreira do indivíduo; organização valoriza os riscos, mesmo existindo erros ocasionais; gestor deve formar um ambiente permissível para que os integrantes da equipe se expressem;

4. Dificuldade para inovação nas empresas de turismo: demanda exigente e nãofiel, grande quantidade de empresas no mercado, pouca mão-de-obra qualificada, falta de planejamento e pesquisa, pouca experiência no negócio (Quadro 2).

Quadro 2 - Siglas das variáveis do instrumento de pesquisa

\begin{tabular}{|c|c|}
\hline Código & Variável \\
\hline CI1 & Novos produtos e serviços de maneira totalmente nova \\
\hline $\mathrm{CI} 2$ & Novos métodos de trabalho \\
\hline $\mathrm{CI} 3$ & Expandir para novos mercados \\
\hline CI4 & Mudança substancial na tecnologia adotada pela organização \\
\hline CI5 & Adotar algo que foi tentado em outro lugar e que teve sucesso \\
\hline MI1 & Acessar novas tecnologias \\
\hline MI2 & Acessar novos mercados \\
\hline MI3 & Aumentar a margem de lucro da empresa \\
\hline MI4 & Desenvolver uma cultura de mercado \\
\hline MI5 & Redução de custos \\
\hline CFI1 & As pessoas são a fonte mais importante dentro do processo de inovação \\
\hline
\end{tabular}




\begin{tabular}{|c|c|}
\hline CFI2 & $\begin{array}{l}\text { É importante que toda a organização, desde o nível da estrutura mais elevado ao mais baixo, } \\
\text { esteja voltada para a inovação }\end{array}$ \\
\hline CFI3 & $\begin{array}{l}\text { Quando uma pessoa tenta uma nova iniciativa e falha, há um sério impacto negativo na carreira do } \\
\text { indivíduo na organização }\end{array}$ \\
\hline CFI4 & Esta organização valoriza os riscos, mesmo existindo erros ocasionais \\
\hline CFI5 & O gestor deve formar um ambiente permissível para que os integrantes da equipe se expressem \\
\hline DI1 & Demanda exigente e não-fiel \\
\hline DI2 & Grande quantidade de empresas no mercado \\
\hline DI3 & Pouca mão-de-obra qualificada \\
\hline DI4 & Falta de planejamento e pesquisa \\
\hline DI5 & Pouca experiência no negócio \\
\hline DT & Discordo totalmente \\
\hline $\mathrm{NC}$ & Não concorda \\
\hline NTC & Não tem certeza \\
\hline $\mathrm{C}$ & Concorda \\
\hline $\mathrm{CT}$ & Concorda totalmente \\
\hline
\end{tabular}

Fonte: Adaptado de Rodrigues (2015)

Para medir as afirmativas dispostas na escala likert entre discordo totalmente e concordo totalmente ou entre nada e totalmente, as categorias foram transformadas para uma escala numérica entre -2 e 2 , sendo -2 igual a Discordo Totalmente e 2 sendo igual a Concordo Totalmente. Dessa forma, nessa nova escala os valores negativos representam uma discordância ou que não sente ser uma situação conflitiva e os valores positivos representam uma concordância ou que sentem ser uma situação conflitiva, já o valor zero representa uma situação neutra. Esse tipo de transformação é sugerido por (Gelman \& Hill, 2007). Para descrever e comparar os itens de cada constructo foi utilizado a média e o intervalo de $95 \%$ de confiança, assim como os percentuais das respostas para cada categoria. As análises estatísticas foram realizadas no software R (versão 3.2.0).

\section{A PERCEPÇÃO SOBRE INOVAÇÃO DOS GESTORES DAS MPE'S TURÍSTICAS}

Para verificar a percepção dos gestores das MPE's turísticas, sobre inovação, dividiuse em 4 constructos (Quadro 3). Pode-se destacar que: 
Quadro 3 - Medidas descritivas e percentuais para os itens dos constructos "Conceito de inovação",

"Motivos para inovar", "Confiança como fator para inovar" e "Dificuldades para a inovação"

\begin{tabular}{|c|c|c|c|c|c|c|c|c|c|}
\hline Constructo & Questão & Média & D.P & L.C $-95 \%$ & & $\%$ & spond & & \\
\hline \multirow{5}{*}{$\begin{array}{l}\text { Conceito de } \\
\text { inovação }\end{array}$} & & & & & DT & NC & NTC & C & CT \\
\hline & CI1 & 1,16 & 1,00 & {$[0,84 ; 1,44]$} & $5 \%$ & $2 \%$ & $7 \%$ & $44 \%$ & $42 \%$ \\
\hline & $\mathrm{CI} 2$ & 1,02 & 1,04 & {$[0,72 ; 1,33]$} & $0 \%$ & $14 \%$ & $9 \%$ & $37 \%$ & $40 \%$ \\
\hline & $\mathrm{CI} 3$ & 0,91 & 1,11 & {$[0,58 ; 1,21]$} & $7 \%$ & $7 \%$ & $2 \%$ & $56 \%$ & $28 \%$ \\
\hline & CI4 & 0,81 & 0,98 & {$[0,51 ; 1,09]$} & $2 \%$ & $7 \%$ & $23 \%$ & $42 \%$ & $26 \%$ \\
\hline \multirow{5}{*}{$\begin{array}{c}\text { Motivos } \\
\text { para inovar }\end{array}$} & CI5 & 0,63 & 1,33 & {$[0,23 ; 1,02]$} & $9 \%$ & $16 \%$ & $7 \%$ & $37 \%$ & $30 \%$ \\
\hline & MI1 & 1,09 & 1,04 & {$[0,79 ; 1,40]$} & $5 \%$ & $2 \%$ & $14 \%$ & $37 \%$ & $42 \%$ \\
\hline & MI2 & 1,28 & 0,83 & {$[1,02 ; 1,51]$} & $0 \%$ & $5 \%$ & $9 \%$ & $40 \%$ & $47 \%$ \\
\hline & MI3 & 1,35 & 0,72 & {$[1,14 ; 1,54]$} & $0 \%$ & $2 \%$ & $7 \%$ & $44 \%$ & $47 \%$ \\
\hline & MI4 & 1,23 & 0,68 & {$[1,02 ; 1,42]$} & $0 \%$ & $0 \%$ & $14 \%$ & $49 \%$ & $37 \%$ \\
\hline \multirow{5}{*}{$\begin{array}{l}\text { Confiança } \\
\text { como fator } \\
\text { para inovar }\end{array}$} & MI5 & 0,79 & 1,04 & {$[0,47 ; 1,07]$} & $2 \%$ & $9 \%$ & $23 \%$ & $37 \%$ & $28 \%$ \\
\hline & CFI1 & 1,47 & 0,51 & {$[1,33 ; 1,61]$} & $0 \%$ & $0 \%$ & $0 \%$ & $53 \%$ & $47 \%$ \\
\hline & $\mathrm{CFI} 2$ & 1,40 & 0,76 & {$[1,16 ; 1,61]$} & $0 \%$ & $5 \%$ & $2 \%$ & $42 \%$ & $51 \%$ \\
\hline & CFI3 & 0,16 & 1,34 & {$[-0,23 ; 0,56]$} & $16 \%$ & $16 \%$ & $19 \%$ & $33 \%$ & $16 \%$ \\
\hline & CFI4 & 0,86 & 0,92 & {$[0,58 ; 1,12]$} & $2 \%$ & $5 \%$ & $21 \%$ & $49 \%$ & $23 \%$ \\
\hline \multirow{6}{*}{$\begin{array}{c}\text { Dificuldades } \\
\text { para a } \\
\text { inovação }\end{array}$} & CFI5 & 1,40 & 0,73 & {$[1,19 ; 1,61]$} & $0 \%$ & $2 \%$ & $7 \%$ & $40 \%$ & $51 \%$ \\
\hline & DI1 & 0,47 & 1,28 & {$[0,07 ; 0,84]$} & $5 \%$ & $26 \%$ & $16 \%$ & $26 \%$ & $28 \%$ \\
\hline & DI2 & 0,12 & 1,31 & {$[-0,23 ; 0,51]$} & $7 \%$ & $40 \%$ & $7 \%$ & $28 \%$ & $19 \%$ \\
\hline & DI3 & 0,91 & 1,21 & {$[0,51 ; 1,26]$} & $7 \%$ & $7 \%$ & $14 \%$ & $33 \%$ & $40 \%$ \\
\hline & DI4 & 1,21 & 0,94 & {$[0,91 ; 1,49]$} & $2 \%$ & $5 \%$ & $7 \%$ & $42 \%$ & $44 \%$ \\
\hline & DI5 & 0,72 & 1,22 & {$[0,37 ; 1,07]$} & $2 \%$ & $21 \%$ & $14 \%$ & $28 \%$ & $35 \%$ \\
\hline
\end{tabular}

Fonte: Rodrigues (2015)

Conceito de inovação

Sobre conceito de inovação os respondentes tenderam a concordar com todos os itens desse constructo (CI1, CI2, CI3, CI4 e CI5), porém o item CI1 (Novos produtos e serviços de maneira totalmente nova) foi o que apresentou o maior nível médio de concordância $(1,16)$. A criação de novos produtos e serviços indiscutivelmente apontada como inovação, ou relatado pelos mais diversos autores, como: Schumpeter (1961); Sundbo e Gallouj (1998); OECD (2004); Rodrigues e Rodrigues (2009); João, et al (2011); Brasil (2014); Drucker (2014); Tadeu (2014); Iordache (2015). 
Ressalta-se que no item CI5 (Adotar algo que foi tentando em outro lugar e que teve sucesso) o menor nível médio de concordância $(0,63)$. Segundo Yazigi (2014), os fazedores de marketing bem sabem que inovações são consideradas nomadismos oriundos de soluções já existentes alhures. Para Tidd e Hull (2005) as estratégias adaptativas podem funcionar adequadamente para alguns temas na área de serviços, mas podem ser armadilhas quando o tema é a inovação, dada a natureza peculiar que o processo de projeto e gestão da operação de serviços possui.

As inovações incrementais são aqueles em que há melhorias moderadas nos produtos e processos de negócios em vigor (Davila, Epstein, \& Shelton, 2007). As organizações para adotarem algo que teve sucesso em outro local, muito possivelmente terão que incrementar para os moldes do ambiente em que estão localizadas, a cultura da organização, etc. Silva (2011) aponta em sua pesquisa que a Rota Alemã, ponto de surgimento da Rota Romântica Gaúcha, possui mais de 50 anos, apresenta algumas características que devem ser seguidas pela brasileira, para que se consolide mais no mercado turístico, trazendo benefícios a localidade. Váldes (2003) informa em sua pesquisa que os destinos turísticos deverão se adaptar a uma situação de competitividade extrema, para satisfação dos stakeholders, em que a obtenção de lucros e a sustentabilidade dos negócios turísticos serão muito mais complexos. Uma adaptação é se moldar, ajeitar, adequar, em que nem sempre passa por uma mudança total.

Uma ferramenta de grande valor para as organizações é o benchmarking, apontada por Drucker (2011), como o melhor desempenho conhecido, pressupondo que o que uma organização faz, qualquer outra pode fazer e que ser tão boa quanto à líder é um pré-requisito para ser competitiva.

Motivos para inovar

Quanto aos motivos para inovar os respondentes tenderam a concordar com todos os itens desse constructo (M11, M12, M13, M14 e M15), sendo que o item MI3 (Aumentar a margem de lucro da empresa) foi o que apresentou o maior nível médio de concordância (1,35), enquanto que o item MI5 (Adotar Redução de custos) o menor nível médio de concordância $(0,79)$. Tellechea (2013) aponta que lucro obtido e apurado na exploração de certa atividade econômica, sendo a razão para inovar. Tadeu (2014), explica que a ampliação do lucro é uma característica para o desenvolvimento de novos produtos. 
A redução de custos foi colocada em segundo plano para os gestores, em que alguns (23\%) tiveram dúvida se a inovação traria o benefício da redução dos custos na empresa. Para Gorni, Dreher e Machado (2009) informam que com intuito de reduzir custos as organizações que prestam serviços seguem em busca da inovação. De acordo com Zehrer, Pechlaner e Reuter (2013) a competitividade das empresas de turismo depende da capacidade de inovação em conseguir custos mais baixos.

Confiança como fator para inovar

$\mathrm{Na}$ questão da confiança para inovar os respondentes tenderam a concordar com os itens CFI1 (As pessoas são a fonte mais importante dentro do processo de inovação), CFI2 (É importante que toda a organização, desde o nível da estrutura mais elevado ao mais baixo, esteja voltada para a inovação), CFI4 (Esta organização valoriza os riscos, mesmo existindo erros ocasionais) e CFI5 (O gestor deve formar um ambiente permissível para que os integrantes da equipe se expressem), enquanto que para o item CFI3 (Quando uma pessoa tenta uma nova iniciativa e falha, há um sério impacto negativo na carreira do indivíduo na organização) os indivíduos não tendem nem a concordar nem a discordar.

Mesmos havendo um equilíbrio nas respostas da variável CFI3, a maior quantidade de respostas foi $33 \%$ dos respondentes concordando, havendo um choque entre as variáveis CFI1 e CFI5. Para Rush (2005) a confiança gera segurança e certeza, dois pré-requisitos para inovação. $\mathrm{O}$ impacto negativo na carreira de um colaborador quanto tenta uma nova iniciativa e falha produz frustração, insegurança e medo; muitas vezes para conservar o emprego, em que são os maiores obstáculos ao desenvolvimento da ação inovadora. Caso seja aplicada a pesquisa com outros respondentes as respostas serão bastante diversificadas.

$\mathrm{Na}$ variável CFI4 (Esta organização valoriza os riscos, mesmo existindo erros ocasionais), $21 \%$ dos gestores responderam que não tem certeza. Entretanto, já foi comentado que no empreendedorismo, assumir riscos é uma característica inerente do empreendedor. Penalva (2015) informa que para Bicalho, uma nova ideia na empresa pode surgir das pessoas que estão no dia a dia na operação.

Dificuldades para inovação

No constructo das dificuldades para inovação, os respondentes tenderam a concordar com os itens DI1 (Demanda exigente e não-fiel), DI3 (Pouca mão-de-obra qualificada), DI4 
(Falta de planejamento e pesquisa) e DI5 (Pouca experiência no negócio), enquanto que para DI2 (Grande quantidade de empresas no mercado) os indivíduos não tendem nem a concordar nem a discordar, devendo sempre variar as respostas de outros respondentes. Para Smith (2006) desafios como a necessidade de intermediários para alcançar mercados mais distantes, a dificuldade de comunicação com inúmeras outras empresas e a escassez de pesquisas, estão relacionados ao fato de haver muitas pequenas empresas. Fortes (2010) vai ao encontro da maior parte dos respondentes (40\%), que não concordaram com variável DI2, no sentido de que para o autor a rivalidade das empresas fomenta o processo de inovação. Duarte (2013), também menciona que os entrevistos, em sua pesquisa, não se sentiam ameaçados por seus concorrentes, nem pela inserção de novas empresas.

\section{CONSIDERAÇÕES FINAIS}

A presente pesquisa teve como objetivo verificar a percepção, sobre inovação, dos gestores das MPE's turísticas do bairro da Praia Grande, Centro Histórico de São Luís-MA. O estudo revelou que os gestores das MPE's turísticas possuem, no geral, boa percepção sobre inovação. No turismo, assim como nas diversas atividades empresariais, a inovação é fator para alcance de resultados satisfatórios para as organizações movidas pelas mudanças exigidas pelos diversos mercados, seja consumidor ou concorrente; trazem novas realidades, situações, dificuldades.

Para desenvolver inovação é necessário um aprofundamento maior das diversas realidades e particularidades dos destinos turísticos compreendendo melhor as realidades, para maior aproveitamento das capacidades dos diversos setores. Os gestores das organizações devem entender o que é inovação, e quais são os seus tipos; implementando e aperfeiçoando o seu processo: as motivações no mercado, o comportamento da equipe para os resultados esperados, bem como, as limitações da empresa para inovar. Indicam-se mais estudos com as empresas pesquisadas, bem como, em outros destinos turísticos, para aprofundamento no assunto.

Compreende-se por meio deste estudo que a maior parte dos gestores tende a concordar com os "conceitos" de inovação, sendo que para os que gerenciam as MPE's turísticas no Bairro da Praia Grande, indiscutivelmente novos produtos e serviços totalmente novos são inovação. A maior aceitação quanto aos "motivos" para inovar foi aumentar a margem de lucro da empresa, comprovando a grande necessidade das organizações em gerar riquezas. 
Relacionado à "confiança" como fator para inovar existe uma incoerência, pois se os gestores devem ter as pessoas como a fonte mais importante dentro do processo de inovação, permitindo um ambiente para que as pessoas se expressem é necessário que os gestores permitam que os membros da equipe fiquem a vontade para correr riscos dentro da organização no sentido de inovar. No construto "dificuldades" para inovar os indivíduos variam principalmente suas respostas no item grande quantidade de empresas no mercado, sugerindo que esse tipo de ambiente não dificulta o processo de inovação, concordando com pesquisas de outros autores, entretanto, quanto maior o número de concorrentes, maior a quantidade de produtos similares ou substitutos.

Algumas limitações foram encontradas no percurso para a finalização deste trabalho, como, (1) a dificuldade de encontrar o quantitativo de MPE's turísticas no bairro da Praia Grande, mesmo pela pesquisa bibliográfica e documental, quase impossibilitando a continuidade da pesquisa nessa temática, e (2) na aplicação do questionário foi visualizado que as informações passadas pela JUCEMA, não correspondendo a quantidade de empresas encontradas no bairro da Praia Grande, pois muitas empresas estavam fechadas. Alguns gestores não tiveram interesse pela pesquisa, outros trataram a mesma com ironia, alguns gestores alegaram falta de apoio por parte das autoridades e como forma de protesto não iriam contribuir com a mesma. Algumas empresas acordaram de responder o questionário e entregar posteriormente, entretanto, na data de recebimento os mesmos não haviam respondido, sendo que alguns foram respondidos ali mesmo.

\section{REFERÊNCIAS}

Amazonas, I. T. (2014). Gestão ambiental na hotelaria: tecnologias e práticas sustentáveis aplicadas nos hotéis de João Pessoa-PB. Dissertação de Mestrado em Desenvolvimento e Meio Ambiente, Universidade Federal da Paraíba, Paraíba-PB, Brasil.

Andrade, T. N. (2006). Aspectos sociais e tecnológicos das atividades de inovação. São Paulo: Lua nova.

Appolinário, F. (2009). Metodologia da ciência: filosofia e prática da pesquisa. São Paulo: Cengage Learning.

Araújo, A. K. \& Araújo, R. M. (2013). A inovação de processos: um estudo no segmento de restaurante. Cultur - Revista de Cultura e Turismo,7 (3), 176-196.

Araújo, R. M. \& Ernesto Filho, I. (2014). Meios de hospedagem: um estudo sobre marcas no contexto da inovação. Revista Iberoamericana de Turismo, 4 (1), 69-84. 
Bâltescu, C. A. (2015). Trends driving the hotel industry global evolution. case of Romania. Bulletin of the Transilvania University of Brasovs, 8, 81-86.

Bascavusoglu-Moreau, E., Kopera, S. \& Wszendybyl-Skulska, E. (2013). "The role of creativity in development of innovation in tourism". Journal of Entrepreneurship, Management \& Innovation 9, 5-15.

Bessant, J., \& Tidd, J. (2009). Gestão da Inovação. (5a. Ed.). Porto Alegre: Bookman.

Braga, A., Marques, C., \& Braga, V. (2009). La decisión de innovar en las empresas portuguesas: un análisis multivariado. Anais da International Conference of Ibero American Academy of Management, Buenos Aires, 6 .

Bramwell, B. \& Lane, B. (2000). Tourism cooperation and partnerships: policies, practices and sustainability. Clevedon: Channel View.

Brasil. Lei $\mathrm{n}^{\mathrm{o}}$ 10.973, de 2 de dezembro de 2004. Dispõe sobre incentivos à inovação e à pesquisa científica e tecnológica no ambiente produtivo e dá outras providências. Recuperado em de 11 maio, 2015, de http://www.planalto.gov.br/ccivil_03/_ato20042006/2004/lei/110.973.htm.

Boaria, F. (2013). O e-commerce nos meios de hospedagem: principais ferramentas utilizadas pelas redes hoteleiras no Brasil. Dissertação de Mestrado em Turismo e Hotelaria, Universidade do Vale do Itajaí - UNIVALI, Balneário Camboriú., SC, Brasil.

Bouchikhi, H., \& Kimberly, J.R. (2001). It is difficult to innovate: The death of teaching free teacher and the birth of the knowledge entrepreneur, Human Relations, 54, pp. 77-84.

Bramwell, B., \& Lane, B. Tourism cooperation and partnerships: policies, practices and sustainability. Clevedon: Channel View, 2000.

Brue, S. L. (2006). História do pensamento econômico. São Paulo: Thomson Learning.

Brunelli, M. Q., Macedo-Soares, T., Diana L. A. \& Silva, R. F. (2012). Inovação e colaboração no turismo carioca: primeiras evidências empíricas. Revista Brasileira de Pesquisa em Turismo, 6 (3) 80-96.

Cardoso, C. S., \& Batista, S. G. (2013). Inovação da oferta turística com base nos valores locais: um estudo do Geoparque Seridó, RN, Brasil. Caderno Virtual de Turismo, 13(2), 150161.

Carvalho, C. L. (2009). Políticas públicas no turismo brasileiro: a cidade de São Paulo e a construção de sua identidade turística. Tese de Doutorado em Ciências da Comunicação, Universidade de São Paulo, São Paulo- SP, Brasil.

Carvalho, K. D., \& Simões, M. L. N. (2011). Turismo e patrimônio cultural sob o olhar do sujeito-morador: uma leitura do bairro da Praia Grande, São Luís, Maranhão (Brasil). Turismo e Sociedade, 4 (1), 12-31.

Cypriano, C. A. C. (1996). Inovação da tradição e sustentabilidade de estratégias culturais: a hotelaria no circuito do carnaval da Bahia. Turismo em Análise, 7 (2),63-76. 
Davila, T., Epstein, M. J., \& Shelton, R. (2007). As regras da inovação. Porto Alegre: Bookman.

D'arcy, D. \& Omar, M. (2015). “A review and reflection on innovation in tourism and hospitality in English language journal publications". Revue Management et Avenir. 17,121137.

Drucker, P. F. (1985). The discipline of innovation. Haward Business Review, 63 (3).

Drucker, P. F. (2014). Inovação e espírito empreendedor: práticas e princípios. São Paulo: Cengage Learning.

Duarte, C. M. M. F. (2013). Gestão estratégica como ferramenta de competitividade nos engenhos de cana de açúcar do Brejo Paraibano. Dissertação de Mestrado em Administração e Desenvolvimento Rural, Universidade Federal Rural de Pernambuco, Recife-PE, Brasil.

Dzikowski, P. (2014). The design of a sectoral innovation system in the tourism sector in Poland. 2014. Journal of Tourism \& Services, 5,18-29.

Fitzsimmons, J. A., \& Fitzsimmons, M. J. (2000). Administração de serviços: operações, estratégias e tecnologia de informação.(2a Ed.) Porto Alegre: Bookman.

Fundação Nacional de Qualidade [FNQ].(2008) A importância da inovação para a sobrevivência das organizações. Recuperado em 02 maio 2015, de:

http://www.fnq.org.br/informe-se/artigos-e-entrevistas/entrevistas/a-importancia-da-inovacaopara-a-sobrevivencia-das-organizacoes.

Fornari, I. S. (2006). Educação superior em turismo: o profissional de turismo frente às competências exigidas pelo mercado de trabalho do setor hoteleiro em Natal. Dissertação de Mestrado em Políticas e Gestão Públicas; Gestão Organizacional, Universidade Federal do Rio Grande do Norte, Natal, RN, Brasil.

Fortes, V. M. M. (2010). Turismo em Cabo Verde: um estudo da competitividade entre os clusters de Santo Antão-São Vicente e Sal-Boa Vista. Dissertação de Mestrado em Administração, Universidade de Caxias do Sul, Caxias do Sul-RS, Brasil.

Garrido, C. (2009). Innovación en los servicios: aspectos generales y ejemplos de los servicios de telecomunicaciones, el turismo y los servicios bancarios. Comisión Económica para América Latina y el Caribe [CEPAL].

Gadrey, J. (2000). The characterization of the best services: an approach alternative. Review of Income and Wealth, 46,(3), 369-387.

Gândara, J. M.(2010). Inovações no turismo experiencial: casos de sucesso no Brasil e exterior. Recuperado em: 31 agosto, 2015. de:

http://www.uesc.br/cultur/palestras/gandara_josemanoel.pdf.

Gelman A., \& Hill J. (2007). Data Analysis Using Regression and Multilevel/Hierarchical Models. New York: Cambridge University Press. 
Generosi, A. (2011). Natal Luz em Gramado (RS), tradição e inovação: um olhar sobre os fatores que determinam o retorno dos turistas ao evento. Dissertação de Mestrado em Turismo, Universidade de Caxias do Sul. Caxias do Sul-RS, Brasil.

Gorni, P.M., Dreher, M.T. \& Machado, D.D.P.N. (2009). Inovação em serviços turísticos: a percepção desse processo em agências de viagens. Revista Acadêmica: Fgv Ebape, 4, (1).

Gronrros, C. (2004). Marketing: gerenciamento e serviços. (2a Ed.). Rio de Janeiro: Elsevier.

Hall, M. \& Rusher, K. (2004). Estilos de vida de risco? Características empreendedoras de cama e pequeno-almoço na Nova Zelândia. In: R. Thomas, As pequenas empresas no setor de turismo: perspectivas internacionais. UK: Elsevier.

Hamel, G. \& Prahalad, C. K. (2005). Competindo pelo futuro. (19a Ed.). Elsevier.

Hisrich, R. D. \& Peters, M. P. (2004). Empreendedorismo. (5a Ed). Porto Alegre: Bookman.

Hoffman, K. D. \& Bateson, J. E. G. (2009). Princípios de marketing de serviços. São Paulo: Cengage Learning.

Instituto Brasileiro de Geografia e Estatística [IBGE]. (2012). Economia do turismo: uma perspectiva macroeconômica 2003-2009. Estudos e pesquisas, Informação econômica, 18, Rio de Janeiro.

Iordache, C. (2015). Innovation in tourism: between desideratum, development and braking. Strategic policy innovation. Romanian Journal of Marketing. 53-66.

João, B. N., Claro, J., Sarmento, M. B. \& Dias, A. H. (2011). Inovação de valor: o caso Citizen M Hostels. Turismo Visão e Ação, Balneário Camboriú, 13 (3),299-310.

Klement, C. F. F. (2007). "Inovação em serviços: estudo de caso em uma organização da indústria hoteleira brasileira". Tese de Doutorado em Administração, Universidade de São Paulo, São Paulo- SP, Brasil.

Kotler, P. (1993). Princípios de marketing. Rio de Janeiro: Prentice-Hall.

Kotler, P.; Keller, K. L. (2006). Administração de marketing. (12a Ed.). São Paulo: Pearson.

Lazzarotti, F. (2012). Recursos para inovação e desempenho de firmas inovadoras. Tese de Doutorado em Administração e Turismo, Universidade do Itajaí, Biguaçu-SC, Brasil.

Lima, F. O., \& Alves, J. L. (2011). Inovação no setor do turismo: apontamentos do processo inovador através do estudo do Grupo Pestana. Algarve.

Lima, J. C. Júnior. (2014). Proposição de um modelo de inovação em serviços a partir da perspectiva do marketing de serviços. Tese de Doutorado em Administração e Contabilidade, Universidade de São Paulo, São Paulo, SP, Brasil.

Lovelock, C., \& Wright, L. (2004). Serviços: marketing e gestão. São Paulo: Saraiva. 
Malzoni, J. C., \& Malzoni, J. C. (2010). 100 grandes chefs contemporâneos escolhidos por 10 mestres internacionais. São Paulo: SENAC.

Maske, D. C. (2012). Relação entre orientação empreendedora, inovação, orientação para o mercado e desempenho em empresas turísticas. Dissertação de Mestrado em Turismo e Hotelaria, Universidade do Vale do Itajaí, Balneário Camboriú-SC, Brasil.

Menezes, V. O. \& Cunha, S. K. (2014). Inovação como instrumento de desenvolvimento de atividade turística. Observatório de Inovação do Turismo - Revista Acadêmica. 8 (1).

Nagy, A. (2012). A review of tourism and hospitality innovation research. Annals of the University of Oradea, Economic Science Series. (21), 364-370.

Nawrot, L. (2013). Renewable energy sources as a new research area in tourism. Poznan University of Economics Review. 13 (16): pp. 67-82.

Nery, L. A. (2012). Oportunidades no turismo do Rio de Janeiro: alianças entre a prefeitura e o setor privado. Dissertação de Mestrado em Administração, Pontifícia Universidade Católica do Rio de Janeiro - PUC/RIO, Rio de Janeiro-RJ, Brasil.

Niño, F.M. (2009). A oferta de serviços turísticos nos ambientes de comércio online e off-line. Tese de Doutorado em Administração, Universidade de São Paulo, São Paulo, SP, Brasil.

Nogueira, M. G. S. (2012). Capacidade estratégica de resiliência e desempenho organizacional em confiabilidade e inovação. Tese de Doutorado em Administração e Turismo , Universidade do Vale do Itajaí, Biguaçu-SC, Brasil.

Organização para Cooperação e Desenvolvimento Econômico [OECD]. (1997). Manual de Oslo: Diretrizes para coleta e interpretação de dados para inovação,(3a Ed.) Eurostat: Londres.

OECD. Organização para a Cooperação Econômica e Desenvolvimento. (2004). Manual de Oslo: proposta de diretrizes para a coleta e interpretação de dados sobre inovação tecnológica. (3a Ed.)

Peccini, R. (2010). História e cultura da alimentação: a Galeteria Peccini e o patrimônio de Caxias do Sul (1950-1970). Dissertação de Mestrado em Turismo, Universidade de Caxias do Sul, Caxias do Sul-RS, Brasil

Penalva, W. (2015). A ordem é inovar. In: Revista Brasileira de Administração. A regra é inovar. 25, (104), janeiro/fevereiro.

Porter, M. (1999). Competição: Estratégias competitivas essenciais. 11. ed. Rio de Janeiro: Elsevier.

Quandt, C. O. (2009). Inovação Tecnológica. In: Empreendedorismo Tecnológico. Instituto de Engenharia do Paraná: Curitiba.

Rodrigues, G. J. M. (2015). Inovação e Empreendedorismo: percepção das MPE's turísticas no bairro da Praia Grande, Centro Histórico de São Luís-MA. Dissertação de Mestrado em Turismo e Hotelaria Universidade do Vale do Itajaí, Balneário Camboriú, SC, Brasil. 
Rodrigues, A., \& Rodrigues, Á. (2009). Turismo e inovação em espaços rurais: estudo de caso da rede européia de turismo de aldeia. Turismo em Análise, 20 (1),.35-47.

Rodrigues, L. D., \& Silva, R. L. (1998). Mas afinal, como influenciar a criatividade nas organizações?. Caderno de Pesquisa em Administração, 1(7).

Rush, M. (2005). Administração: uma abordagem bíblica. Belo Horizonte: Betânia.

Sandoval, E. C. \& Cano, L. Z. (2014). "Innovation as a competitive factor in tourist companies in Cancun, Quintana Roo, Mexico". Revista Internacional Administracion \& Finanzas (RIAF), 7 (6).

Say, J. B. (1880). A treatise on political economy. (C. R. Prinsep, P.A. Filadelfia, C. Remsen \& Haffelfinger, Trad.) (Originalmente publicado em 1803).

Schumpeter, J. A. (1950). Capitalism, socialism, and democracy.(3a Ed.). Nova York: Harper. (Originalmente publicado em 1942).

Schumpeter, J. A. (1961). Capitalismo, sociedade e democracia. Rio de Janeiro: Fundo de Cultura.

Silva, M. A. (2007). "ENTRAI - Encontro das tradições italianas: festa popular patrimônio cultural, lazer e turismo". Dissertação de Mestrado em Turismo. Universidade de Caxias do Sul. Caxias do Sul-RS, Brasil.

Silva, P. M. (2011). A Rota Romântica: uma análise das inovações sociais decorrentes de um empreendimento turístico. Dissertação de Mestrado em Administração. Universidade do Vale do Rio Sinos, São Leopoldo-RS, Brasil.

Silva, R. de A. (1997). Proposta do Governo do Estado do Maranhão para inclusão do Centro Histórico de São Luís na lista do Patrimônio Mundial da UNESCO. São Luís.

Siqueira, J. (2009). Inovação: o desafio permanente. Recuperado em 23 de agosto 2015, de http:/criatividadeaplicada.com/2009/03/29/inovacao-o-desafio-permanente.

Smith, S. L. J. (2006). How big, how many? Company size distributions in tourism and other industries. Journal of Travel Research, 12, 243-254.

Sundbo, J. (1997). Management of innovation in services. The Service Industries Journal. London, 17, (3), 432.

Sundbo, J., \& Gallouj, F. (1998). Innovation in services. SI4S Synthesis Paper, (2).

Tadeu, H. F. B. (2014). Panorama da inovação no Brasil. Nova Lima-MG, Fundação Dom Cabral FDC Executive.

Tejada, P. \& Moreno, P. (2013). Patterns of innovation in tourism 'small and medium-size enterprises. Service Industries Journal. 33 (10), 749-758. 
Tellechea, R. (2015). Empreender, inovar e administrar: uma união indefectível. Recuperado em 23 agosto, 2015, de http://www.administradores.com.br/artigos/administracao-enegocios/empreender-inovare-administrar-uniao-indefectivel/69453/\#.

Tidd, J., \& Hull, F. M. (2005). Inovação Serviço: As respostas organizacionais, oportunidades tecnológicas e exigências do mercado. Imperial College Press.

Tomazzoni, E. L. \& Zanirato, S. H. (2014). Inovação e identidade vitivinícola da Festa Nacional da Uva de Caxias do Sul (Rio Grande do Sul, Brasil): os cursos de degustação de vinhos como estratégias de Turismo de Experiência. Turismo e Sociedade, Curitiba, 7 (3): pp. $576-598$.

Tour da experiência. (2015). Experiência em destaque. Recuperado em: http://www.tourdaexperiencia.com.br/inicio.

Trindade, F. M. (2009). Empreendedorismo por mulheres: um estudo com mulheres proprietárias de empresas turísticas em Florianópolis (SC). Dissertação de Mestrado em Turismo e Hotelaria) - Universidade do Vale do Itajaí, São Paulo, Brasil.

Valdés, J. A. (2003). Marketing estratégico e estratégia competitiva de empresas turísticas: um estudo de caso da cadeia hoteleira Sol Meliá. Tese de Doutorado em Administração Universidade de São Paulo, São Paulo, Brasil.

Valadares, C. (2015). A inovação é a alma do negócio. Recuperado em 4 de maio, 2015, de http://www.turismo.gov.br/turismo/noticias/todas_noticias/20141002_2.html.

Valei, G. V., Wilkinson, J., \& Amâncio, R. (2008). Empreendedorismo, inovação e redes: uma nova abordagem. Revista Era. 7 (1).

Varani, C. B. (2009). Caminhos da inovação: Southwest Airlines. Recuperado em 02 maio, 2015, de http://www.plataformai.com.br/v4.0/2009/06/caminhos-da-inovacao-southwestairlines/.

Vargo, S. L., \& Lusch, R. F. (2004). The four myths of marketing services: remains of a good base, manufacturing model. Journal of Marketing Research, Chicago, 6, (4), 324-335.

Vasconcellos, L. H. R., \& Marx, R. (2011). Como ocorrem as inovações em serviços? um estudo exploratório de empresas no Brasil. Gest. Produção, 18 (3), 443-460.

Vergara, S. C. (2011). Projetos e relatórios de pesquisa em administração. 13. ed. São Paulo. Editora Atlas S.A.

Yazigi, E. A. (2014). Criatividade ou Inovação? Espaço e Cultura do Gênio Gaúcho. Revista Rosa dos Ventos, Caxias do Sul (RS), 6 (3), 469-480.

Yu, A. S. O. \& Klement, C. F. F. (2006). "Inovação na indústria hoteleira: complementação entre inovações tecnológicas e inovações baseadas em serviços". Revista Acadêmica. 1 (3).

Zanotto, C. (2015). Relaxamento intefere nos lucros. Revista Brasileira de Administração. A regra é inovar. 25, (104). 
Zehrer, A., Pechlaner, H., \& Reuter, C. (2013). Tourism innovation capacity: the perception of participants of innovation awards. Journal of Tourism, 14 (1). 